the induration of the sore, even when accompanied by its appropriate bubo, the same amount of importance as a means of diagnosis attributed to it by Mr. Lee; for we have to consider that this hardness is frequently wanting in the primary infecting sore; and often, when it is present, it cannot, he says, be detected. We do not find in it that description of character which corresponds to the botanical peculiarities by which one plant is known from another, as, for instance, a rose from a myrtle; which stamp of character in plants is required to be present and discernible, or at least not fugitive or fortuitous. We perceive, however, in the argument before us, two elements concerned: first, a virus which is extraordinary, of exceeding potency and penetrative character; and this may be likened to the seed. The soil is the human body, which becomes vitally affected; and this affection, or reaction of the body, we call physiological, or better, pathological (as to "dynamical", we know not what it is, unless when a man drags in a strange word head over heels). Now this affection of the body is in an onward series, from hour to hour and day to day, without a halt as yet; and it dates from the very beginning of the infection. Nor is this series like a chain with equal links, or even as a flat alluvial plain; but rather as a gradation of steps, or as the uneven ground of a mountain ascent, the soil varying as we advance. And the product of the soil will vary too; for the product of the later period differs from that of the period which precedes, and which soon is left behind; and this is why an inoculation from a hard sore results in a sore without induration; though in direct succession to the former, it carries the virus still.

But that we may not be judged of as slight and inconsiderate, as never giving a thought to the natural form of things, but weaving cobweb dreams out of the films of fancy, we will note down in this place one of those axioms which were the first recorded observations in this path of discovery. The 49th rule or axiom of Auzias-Turenne, in his letter to the Academy of Sciences, Nov. 1850, runs as follows:"When the chancres made upon an ape have a few days interval between each, the induration does not always show itself in the seat of the frst chancre, but not seldom we find it in the second chancre or in the third. But the occurrence of the induration is wholly referrible in point of time to the existence of the first chancre, so as to accompany the second or third in the first day of their development. A pustule of inoculation in one of our patients might, by induration, be followed in the same way."

Let the vain theories of Langlebert go. We see the narrow basis on which rests the artificial system of the French; viz., on infection by the syphilitic blood, a Deus ex machina they are always calling to their aid. Yet, when we remember how insignificant in number are the cases of success from this source in a large body of experimental results-and never are they positive, but when the blood has been applied over a very large extent of surface-we are justified in refusing this mode of explanation, not only in the case before us, but also in the cases of vaccination at Rivalta and elsewhere, as quoted by Mr. Lee in his work on syphilis-cases once more brought into the field of discussion by the experiments of William Boeck with the vaccine matter of syphilitic infants mingled with their blood. In all such difficulties, there is a straigktforward way of looking at a thing, which should take precedence of what is far-fetched and subtle; and we say that there is a vast difference, and one which cannot but be discerned, in the force and quality of syphilitic matter; and that it appears to us that the quality of the matter at Rivalta was exceptional, and that $\stackrel{\$}{\varrho}$ its power was intensified by repeated transmissions $\subseteq$ in a virgin soil. This differenee is fully intelligible $\overrightarrow{\bar{*}}$ in a disorder so many times called Protean; and this $\stackrel{5}{+}$ variety in the matter also serves to explain why the girls in Bidenkap's clinique were not affected by the $\frac{\bar{O}}{\sigma}$ disease, and it explains other circumstances not $\frac{\bar{\omega}}{\bar{c}}$ otherwise easy to be understood.

When the dogma of the non-contagiousness of $\stackrel{\mathbb{}}{\mathbb{Q}}$ secondaries fell, and the year 1859 witnessed its last parting sigh-it is now, as M. Ricord once said of $\omega$ syphilisation, thoroughly dead (bien morte) - the ex- $\overrightarrow{0}$ clusive and almost fetish worship of the chancre was by the same act, and at the same hour, brought to $\overrightarrow{\vec{\omega}}$ an end. M. Ricord put his hand to the deed which authorised his dethronement.* No longer he reigned $\frac{}{\partial}$ a magnificent king. To recur to the language of 3 the worthy Velpeau, used long before, from hence-: forth his school became identified with the setting, is and ours, which is the school of observation, moves $\infty$ onward with the rising sun.†

* In this year (1858), as a result of many scandals, by direction $\vec{\infty}$ of the minister, a committee of the Academy of Medicine was appointed to decide on the fact of contagion by secondaries; and, being a member of the committee appointed, M. Ricord had to record his recantation of his loug cherished doctrine, on the $24 \mathrm{th}$ May, 1859 . + See speech of M. Velpeau, on the debate on Contagion of Secondaries, in Académie de Médecine, 12th October, 1852.

\section{FRACTURE OF THE HUMERUS BY MUSCULAR ACTION.}

By Charles Terry, Esq., Newport Pagnell.

THe patient, J. C., came to me about three months $\frac{\partial}{0}$ ago. He is sixteen years of age, strong, tolerably robust, and showing the very reverse of a rickety $\frac{}{\Phi}$ diathesis. He had just been trying how far he could throw a cricket-ball; and, whilst he was in the $\overrightarrow{\vec{O}}$ act of throwing, his arm dropped. He exclaimed, 3 "My arm is broken," and came to me. On examination, I found a fracture at the junction of the upper with the middle third of the humerus, attended with perfect inability to move the arm, slight displacement, great pain, and considerable crepitus. Had there not been a witness, who corroborated this aocount of the accident, I should have been inclined to 0 doubt my patient's statement. The fracture was put up in the ordinary way, and is now well. The callus can be plainly felt, shewing the point where $\frac{0}{3}$ the fracture occurred.

This case I have considered worthy of being re- 음 corded, as some surgical authorities do not refer to
muscular action as a cause of fracture of the humerus. In other standard works, however, such as $D$ those of Mr. Erichsen and the late Professor Miller, 으. sudden contraction of the muscles of the arm is mentioned as producing fracture in some cases. Mr. N Erichsen, indeed, in his Science and Art of Surgery, N says that fractures of the shaft of the humerus "are $\omega$ more frequently the result of muscular action than are those of any other bone."

Occurrence of Ergot on Different Plants. Dr. Kühn has observed the ergot to occur on twenty- $T$ eight graminaceous and five cyperaceous plants growing in different positions, and on soils of oppo- $\frac{}{\mathbb{D}}$ site qualities. He comes to the conclusion that $\stackrel{\square}{\mathscr{\rho}}$ moist bad soil and low position have little to do with $\stackrel{\mathbb{Q}}{\stackrel{Q}{\alpha}}$ its development. The fungus (Claviceps purpurea, upwards of a million spores, which readily germinate. He reared the ergot from spores placed in flowerpots. (Year-Booli of Pharmacy.) 